\title{
Optimization of Extraction of Natural Pigment from Purple Sweet Potato by Response Surface Methodology and Its Stability
}

\author{
Jinwei Li, ${ }^{1,2}$ Lianfu Zhang, ${ }^{2}$ and Yuanfa Liu ${ }^{2}$ \\ ${ }^{1}$ State Key Laboratory of Dairy Biotechnology, Technology Center, Bright Dairy \& Food Co. Ltd., Shanghai 200436, China \\ ${ }^{2}$ State Key Laboratory of Food Science and Technology, Jiangnan University, Wuxi 214122, China \\ Correspondence should be addressed to Yuanfa Liu; ljw6688@hotmail.com
}

Received 8 November 2012; Revised 19 March 2013; Accepted 2 April 2013

Academic Editor: Mehmet Emin Duru

Copyright (c) 2013 Jinwei Li et al. This is an open access article distributed under the Creative Commons Attribution License, which permits unrestricted use, distribution, and reproduction in any medium, provided the original work is properly cited.

Purple sweet potato colour (PSPC) was a kind of natural pigment that attracted the general concern in recent years. In this paper, the response surface methodology was employed to optimize the extraction conditions of PSPC. The results showed that the extraction yield of purple colour was $11.6355 \mathrm{mg} / \mathrm{g}$ at the optimum extraction conditions of extraction temperature $60^{\circ} \mathrm{C}$, extraction time $1 \mathrm{~h}$, the ratio of solid to liquid ratio of $1: 30$, and acidified ethanol solution concentration $80 \%$. Stability experiment showed that $\mathrm{Fe}^{3+}$ and $\mathrm{Al}^{3+}$ could increase the stability of PSPC, but $\mathrm{Cu}^{2+}, \mathrm{Zn}^{2+}$, and $\mathrm{Pb}^{2+}$ would decrease the stability of PSPC. Ascorbic acidified could significantly increase the stability of PSPC, and $\mathrm{Na}_{2} \mathrm{SO}_{3}$ would reduce the PSPC's stability.

\section{Introduction}

The colour of foods could affect the customer's decision on purchasing behavior by causing customer's direct attention on the sensory. However, the synthetic pigment had a negative impact on human's healthy. More and more attentions are paid to the natural pigment, which could be served as a functional component.

Anthocyanin is one of the most important natural pigments. Purple sweet potato is a plant which is rich in anthocyanin. The anthocyanin from purple sweet potato could be not only used as the natural pigment but also used as the functional compound due to its obvious antioxidant, antimutation, and antineoplastic activities [1-8]. In this paper, the objective was to optimize the extraction condition by response surface methodology and investigate its stability.

\section{Materials and Methods}

2.1. Materials. Fresh purple sweet potato was purchased from Tianheyuan agricultural incorporation in Suzhou.

\subsection{Method}

2.2.1. Pretreatment of Purple Sweet Potatoes. Purple sweet potatoes were washed and chopped into pieces, then they were dried in the oven at $50^{\circ} \mathrm{C}$ for 12 hours. Finally, they were smashed and kept in brown desiccator.

2.2.2. The Maximum Absorbance Wavelength of Purple Sweet Potatoes Pigment. A UV-Vis spectrophotometer (UV2102PCS) was used to determine the maximum absorbance of purple sweet potato pigment. Purple sweet potato powder was weighted and extracted in acidified ethanol aqueous solution at $60^{\circ} \mathrm{C}$ for one hour. Then, it was centrifuged at $5000 \mathrm{r} / \mathrm{min}$ for $15 \mathrm{~min}$. The $\mathrm{pH}$ of supernatant was adjusted to 2 , and then the supernatant was scanned from $200 \mathrm{~nm}$ to $700 \mathrm{~nm}$.

2.2.3. Optimization of Extraction of Purple Sweet Potato Pigment. A RSM was used to optimize the extraction conditions for purple sweet potato pigment. A multivariate study based on Box-Behnken design was chosen to evaluate effects of extraction parameters. The four independent variables were 
TABLE 1: The coding schedule of response surface methodology.

\begin{tabular}{lcccc}
\hline Independent variable/unit & \multirow{2}{*}{ Symbol } & \multicolumn{3}{c}{ Level } \\
& & -1 & 0 & 1 \\
\hline Extraction temperature $/{ }^{\circ} \mathrm{C}$ & $X_{1}$ & 55 & 60 & 65 \\
Time/min & $X_{2}$ & 50 & 60 & 70 \\
Solid-liquid ratio/1: $X$ & $X_{3}$ & 25 & 30 & 35 \\
$\begin{array}{l}\text { Acidified ethanol aqueous solution } \\
\text { concentration/\% }\end{array}$ & $X_{4}$ & 75 & 80 & 85 \\
\hline
\end{tabular}

extraction temperature $\left(X_{1}\right)$, extraction time $\left(X_{2}\right)$, solidliquid ratio $\left(X_{3}\right)$, and acidified ethanol aqueous solution concentration $\left(X_{4}\right)$, and three levels of each independents were chosen for study. The coded values of the three independent variables were summarized in Table 1 . The response value was the anthocyanin yield that was calculated from the absorption measured at $525 \mathrm{~nm}$ by a UV-Vis diode array spectrophotometer.

2.2.4. Experiment of Verification. $1.0000 \mathrm{~g}$ purple sweet potato powder was weighted and PSPC was extracted according to the conditions which were optimized by RSM, and the results were compared with the modeling value.

\subsubsection{Stability of PSPC.}

(1) Effect of Metal Ion on PSPC Stability. $\mathrm{CuSO}_{4}, \mathrm{FeCl}_{3}$, $\mathrm{AlCl}_{3}, \mathrm{PbCl}_{2}$, and $\mathrm{ZnSO}_{4}$ were weighted and added in PSPC solutions with the $\mathrm{Fe}^{3+}, \mathrm{Cu}^{2+}, \mathrm{Al}^{3+}, \mathrm{Pb}^{2+}$, and $\mathrm{Zn}^{2+}$ concentration of $100 \mathrm{mg} / \mathrm{L}$. The $\mathrm{pH}$ value was controlled at 2 and was kept away from light at room temperature. Measure its absorption at $0 \mathrm{~h}, 24 \mathrm{~h}$, and $48 \mathrm{~h}$.

(2) Effect of Food Additives on PSPC Stability. $\mathrm{Na}_{2} \mathrm{SO}_{3}$, ascorbic acid were weighted and added in PSPC solutions with the different concentration. The solutions were kept away from light at room temperature for $2 \mathrm{~h}$ and then measured its absorption at $525 \mathrm{~nm}$.

\section{Results and Discussion}

3.1. Measurement of the Maximum Absorption Wavelength. As shown in Figure 1, there are three peaks at $280 \sim 290 \mathrm{~nm}$, $320 \sim 340 \mathrm{~nm}$, and $520 \sim 530 \mathrm{~nm}$. The peak at $280 \sim 290 \mathrm{~nm}$ is the characteristic absorption peak of polyphenol, the peak at $320 \sim 340 \mathrm{~nm}$ is the characteristic absorption peak of organic acid, and the peak located at 520 530 $\mathrm{nm}$ is the characteristic absorption peak of anthocyanins. The peak at $520 \sim 530 \mathrm{~nm}$ is chosen as testing wavelength.

3.2. Effect of Extractant on the PSPC Yield. As shown in Figure 2, compared with the other extractant, acidified methanol has the highest PSPC yield, followed by acidified ethanol aqueous solution, $5 \% \mathrm{HCl}$. Considering its use on food, safety, and cost, the acidified ethanol aqueous solution is chosen as the appropriate extractant.

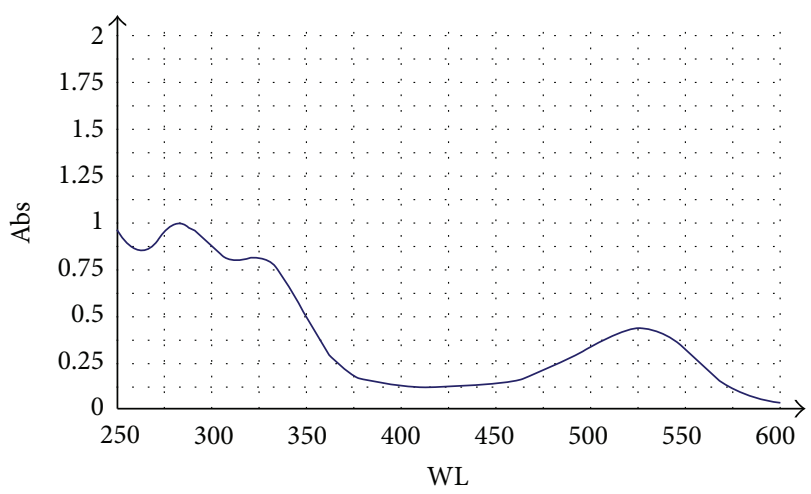

FIGURE 1: Full wavelength scan of PSPC.

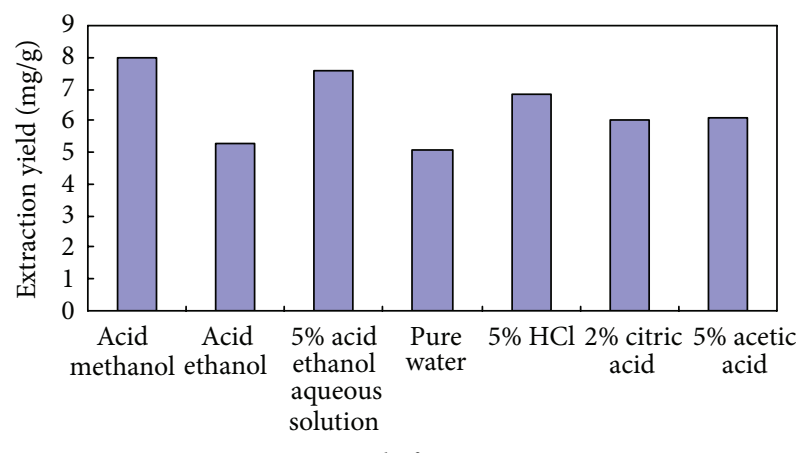

Kind of extractant

FIGURE 2: Effect of the kind of extractant on extraction ratio of PSPC.

3.3. Results of RSM Experiment. The results of RSM analysis of the variation of PSPC yield with extraction temperature $\left(X_{1}\right)$, extraction time $\left(X_{2}\right)$, solid-liquid ratio $\left(X_{3}\right)$, and acidified ethanol aqueous solution concentration $\left(X_{4}\right)$ are shown in Table 2. SAS multivariate regression program was used to analyze the data, and quadratic regression model of extraction temperature, time, solid-liquid ratio, and acidified ethanol aqueous solution concentration is as follows:

$$
\begin{aligned}
Y= & 24.93767-0.113417 X_{1}-0.106833 X_{2}-0.071 X_{3} \\
& -0.50075 X_{4}-1.490042 X_{1}^{2}-0.0465 X_{1} X_{2} \\
& -0.2835 X_{1} X_{3}+0.64975 X_{1} X_{4}-1.090667 X_{2}^{2} \\
& -0.19725 X_{2} X_{3}-0.09475 X_{2} X_{4}-1.173917 X_{3}^{2} \\
& +0.44675 X_{3} X_{4}-0.902542 X_{4}^{2}
\end{aligned}
$$

3.4. Analysis of Variance (ANOVA) of Quadratic Regression Model. ANOVA of quadratic regression model (Table 3) demonstrated that the variables were adequately fitted to the regression equation (1), which were statistically acceptable at $P<0.05$ level and adequate with satisfactory determination coefficients ( $R^{2}$ of 0.9768 and $R_{\text {Adj }}^{2}$ of 0.9468$)$. The PSPC yield was significantly affected by linear term $X_{4}$, quadratic terms $X_{1}^{2}, X_{2}^{2}, X_{3}^{2}$, and $X_{4}^{2}$, and interactions terms of $X_{1}$ and $X_{3}, X_{1}$ and $X_{4}, X_{3}$, and $X_{4}$. According to the $F$ value, the significance 


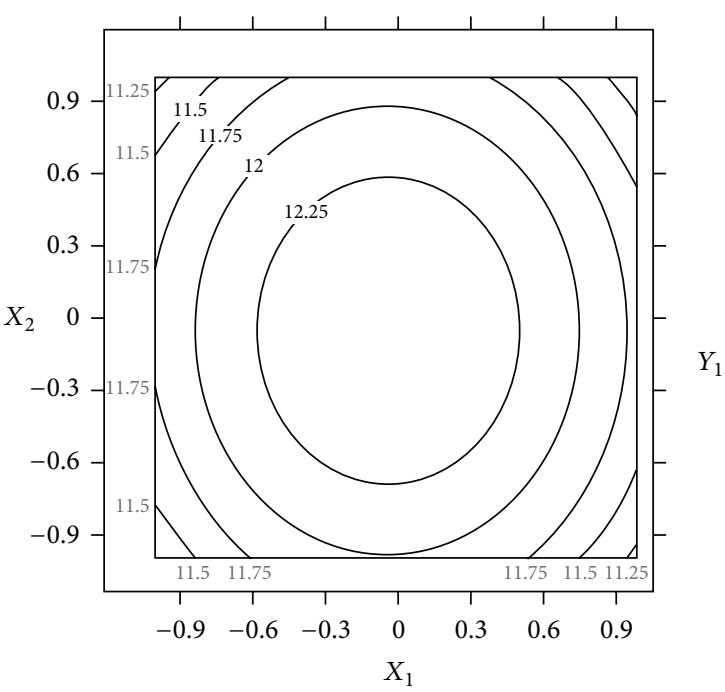

- $Y_{1} \quad$ Fixed levels: $X_{3}=0, X_{4}=0$

(a)

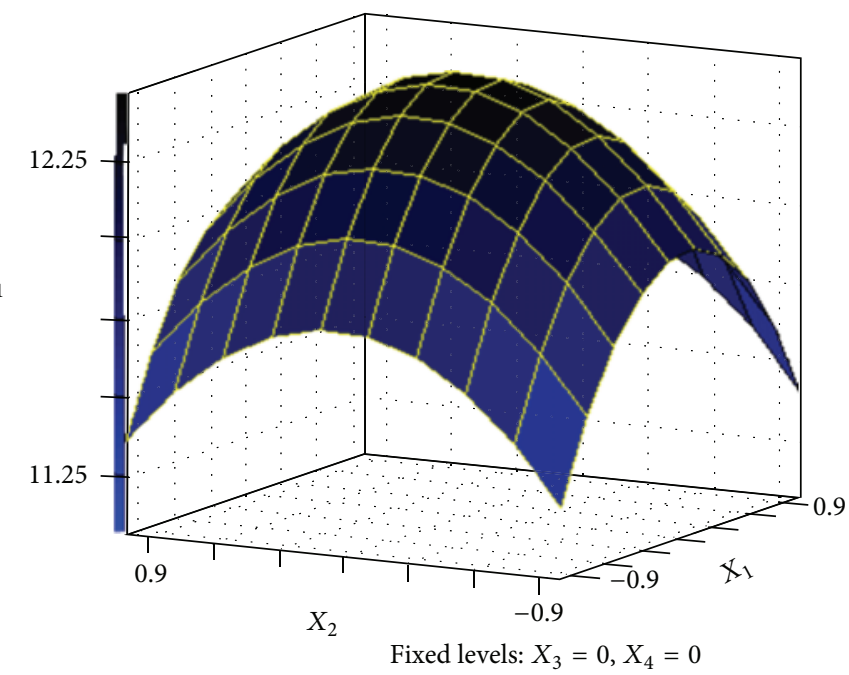

(b)

FIGURE 3: Contour plot and response surface diagram of effect between extraction temperature and time on PSPC.

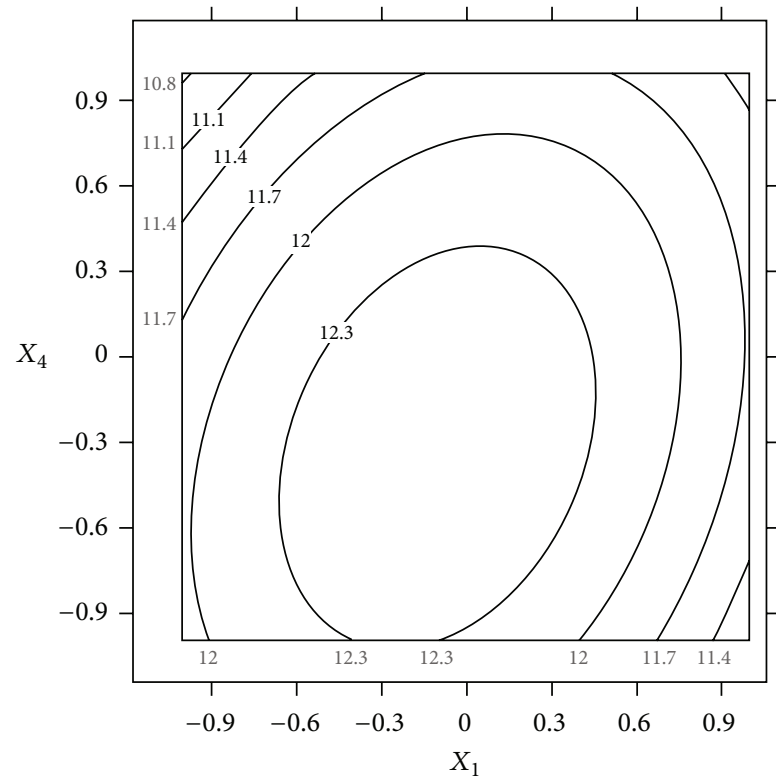

$Y_{1} \quad$ Fixed levels: $X_{2}=0, X_{3}=0$

(a)

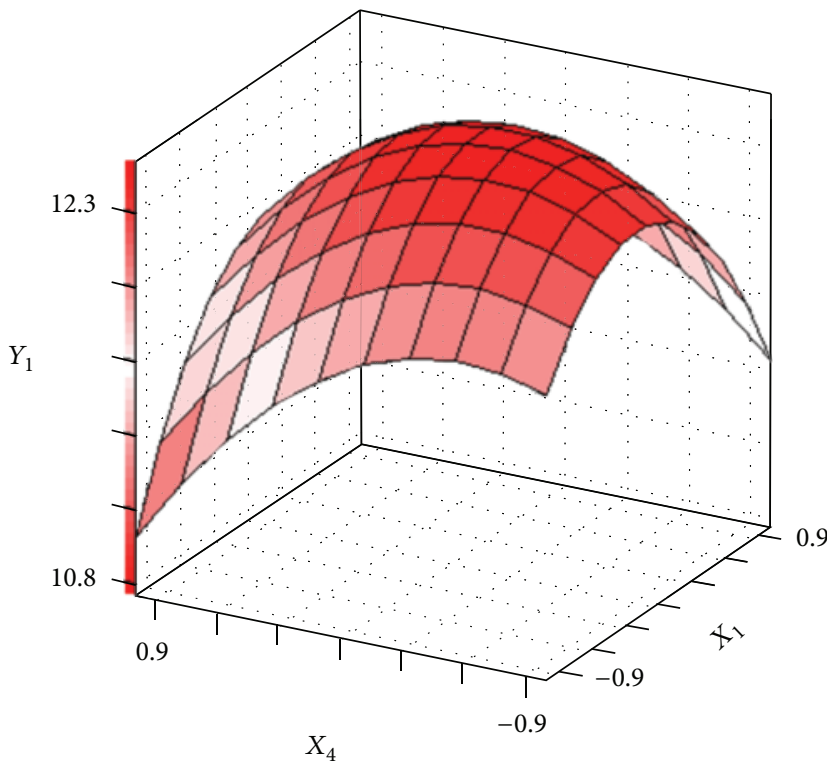

Fixed levels: $X_{2}=0, X_{3}=0$

(b)

FIGURE 4: Contour plot and response surface diagram on effect between extraction temperature and concentration of acidified ethanol on PSPC.

orders of the parameters for the PSPC yield in the prediction model were $X_{4}>X_{1}>X_{2}>X_{3}$.

3.5. Optimum Extraction Condition for PSPC. Threedimensional diagram and contour plot made by full model of (1) were used to predict the relationships between the extraction temperature, extraction time, and PSPC yield (Figure 3). When the extraction temperature and extraction time increased, the PSPC yield increases firstly and then decreases. At the medium value of extraction condition of temperature and time, the PSPC has the higher extraction yield (Figure 3 ). The contour plot showed that the optimum extraction temperature is between 57.1 and $62.55^{\circ} \mathrm{C}$ and the optimum extraction time is between 56.6 and $62.95 \mathrm{~min}$.

Three-dimensional diagram and contour plot were used to predict the relationships between the extraction 
TABLE 2: Results of Box-Behnken of response surface methodology.

\begin{tabular}{|c|c|c|c|c|c|}
\hline Test code & $X_{1}$ & $X_{2}$ & $X_{3}$ & $X_{4}$ & $Y(\mathrm{mg} / \mathrm{g})$ \\
\hline 1 & -1 & -1 & 0 & 0 & 11.3175 \\
\hline 2 & -1 & 1 & 0 & 0 & 11.1425 \\
\hline 3 & 1 & -1 & 0 & 0 & 11.3365 \\
\hline 4 & 1 & 1 & 0 & 0 & 11.0685 \\
\hline 5 & 0 & 0 & -1 & -1 & 11.9935 \\
\hline 6 & 0 & 0 & -1 & 1 & 10.9165 \\
\hline 7 & 0 & 0 & 1 & -1 & 11.5735 \\
\hline 8 & 0 & 0 & 1 & 1 & 11.3900 \\
\hline 9 & -1 & 0 & 0 & -1 & 11.8120 \\
\hline 10 & -1 & 0 & 0 & 1 & 10.7630 \\
\hline 11 & 1 & 0 & 0 & -1 & 11.1080 \\
\hline 12 & 1 & 0 & 0 & 1 & 11.3585 \\
\hline 13 & 0 & -1 & -1 & 0 & 11.3780 \\
\hline 14 & 0 & -1 & 1 & 0 & 11.3700 \\
\hline 15 & 0 & 1 & -1 & 0 & 11.4760 \\
\hline 16 & 0 & 1 & 1 & 0 & 11.0735 \\
\hline 17 & -1 & 0 & -1 & 0 & 11.3995 \\
\hline 18 & -1 & 0 & 1 & 0 & 11.0815 \\
\hline 19 & 1 & 0 & -1 & 0 & 10.8575 \\
\hline 20 & 1 & 0 & 1 & 0 & 11.1065 \\
\hline 21 & 0 & -1 & 0 & -1 & 11.6355 \\
\hline 22 & 0 & -1 & 0 & 1 & 11.2575 \\
\hline 23 & 0 & 1 & 0 & -1 & 11.7305 \\
\hline 24 & 0 & 1 & 0 & 1 & 11.1630 \\
\hline 25 & 0 & 0 & 0 & 0 & 12.4465 \\
\hline 26 & 0 & 0 & 0 & 0 & 12.4800 \\
\hline 27 & 0 & 0 & 0 & 0 & 12.4800 \\
\hline
\end{tabular}

temperature and concentration of acidified ethanol solution and PSPC yield (Figure 4). When the extraction temperature and the concentration of acidified ethanol aqueous solution increased, the PSPC yield increased before the medium level and then decreases. The contour plot showed that the optimum extraction temperature is between 55 and $62^{\circ} \mathrm{C}$ and the optimum concentration of acidified ethanol aqueous solution is between $76.7 \%$ and $82.25 \%$.

According to the results of the analysis of regression model, the optimum conditions for the extraction of PSPC are at the extraction temperature of $60^{\circ} \mathrm{C}$, time of $1 \mathrm{~h}$, solid-liquid ratio of $1: 30$, acidified ethanol aqueous solution concentration of $80 \%$, and the extraction yield could reach $11.6355 \mathrm{mg} / \mathrm{g}$.

3.6. Verification Experiment. The extraction experiments were carried out under the optimum conditions of extraction temperature $60^{\circ} \mathrm{C}$, time $1 \mathrm{~h}$, solid-liquid ratio $1: 30$, and acidified ethanol aqueous solution concentration of $80 \%$. The real PSPC yield was $11.5276 \mathrm{mg} / \mathrm{g}$, which was adjacent to the modeling value of $11.6355 \mathrm{mg} / \mathrm{g}$ with standard error of $0.93 \%$. This result indicates that this regression model could be used to indicate the relationship between extraction condition and PSPC yield and to predict the extraction yield of PSPC.
TABLE 3: Analysis of variance of regression model.

\begin{tabular}{lccccc}
\hline Source & DF & SS & MS & $F$ & $\operatorname{Pr}>F$ \\
\hline$X_{1}$ & 1 & 0.15436 & 0.15436 & 3.509213 & 0.085582 \\
$X_{2}$ & 1 & 0.13696 & 0.13696 & 3.113648 & 0.103052 \\
$X_{3}$ & 1 & 0.060492 & 0.060492 & 1.375222 & 0.263671 \\
$X_{4}$ & 1 & 3.009007 & 3.009007 & 68.40659 & 0.0001 \\
$X_{1} \times X_{1}$ & 1 & 11.8412 & 11.8412 & 269.1971 & 0.0001 \\
$X_{1} \times X_{2}$ & 1 & 0.008649 & 0.008649 & 0.196626 & 0.665347 \\
$X_{1} \times X_{3}$ & 1 & 0.321489 & 0.321489 & 7.308713 & 0.019186 \\
$X_{1} \times X_{4}$ & 1 & 1.6887 & 1.6887 & 38.39082 & 0.0001 \\
$X_{2} \times X_{2}$ & 1 & 6.344287 & 6.344287 & 144.2307 & 0.0001 \\
$X_{2} \times X_{3}$ & 1 & 0.15563 & 0.15563 & 3.538089 & 0.084454 \\
$X_{2} \times X_{4}$ & 1 & 0.03591 & 0.03591 & 0.816382 & 0.38402 \\
$X_{3} \times X_{3}$ & 1 & 7.349762 & 7.349762 & 167.0891 & 0.0001 \\
$X_{3} \times X_{4}$ & 1 & 0.798342 & 0.798342 & 18.14947 & 0.001107 \\
$X_{4} \times X_{4}$ & 1 & 4.344434 & 4.344434 & 98.76612 & 0.0001 \\
Model & 14 & 22.27012 & 1.590723 & 36.16341 & 0.0001 \\
Error & 12 & 0.527845 & 0.043987 & & \\
Total & 26 & 22.79797 & & & \\
\hline$R^{2}=97.68 \% R_{\text {Adj }}^{2}=94.68 \%$. & & &
\end{tabular}

TABLE 4: Effects of metallic ion on PSPC stability.

\begin{tabular}{lcccccc}
\hline \multirow{2}{*}{ Time (h) } & \multicolumn{5}{c}{ Absorbance value $(A)$} \\
& $\mathrm{Fe}^{3+}$ & $\mathrm{Zn}^{2+}$ & $\mathrm{Cu}^{2+}$ & $\mathrm{Pb}^{2+}$ & $\mathrm{Al}^{3+}$ & Blank \\
\hline 0 & 0.752 & 0.752 & 0.752 & 0.752 & 0.752 & 0.752 \\
24 & 0.750 & 0.721 & 0.745 & 0.744 & 0.749 & 0.746 \\
48 & 0.748 & 0.710 & 0.742 & 0.743 & 0.748 & 0.745 \\
\hline
\end{tabular}

3.7. Effect of Metal Ion on PSPC Stability. Effects of metal ion on PSPC stability is shown in Table 4. Compared with bank solution, the solution with $\mathrm{Fe}^{3+}$ or $\mathrm{Al}^{3+}$ has the higher absorbance value at $525 \mathrm{~nm}$ for $24 \mathrm{~h}$ and $48 \mathrm{~h}$, which meant that $\mathrm{Fe}^{3+}$ or $\mathrm{Al}^{3+}$ contributed to the PSPC stability. However, the solution with $\mathrm{Cu}^{2+}, \mathrm{Zn}^{2+}$, or $\mathrm{Pb}^{2+}$ has the lower absorbance value at $525 \mathrm{~nm}$ for $24 \mathrm{~h}$ and $48 \mathrm{~h}$, which meant that $\mathrm{Cu}^{2+}, \mathrm{Zn}^{2+}$ or $\mathrm{Pb}^{2+}$ was against the PSPC stability.

3.8. Effect of Ascorbic Acid and $\mathrm{Na}_{2} \mathrm{SO}_{3}$ on PSPC Stability. Effects of ascorbic acid and $\mathrm{Na}_{2} \mathrm{SO}_{3}$ on PSPC stability is shown in Table 5. The absorbance value at $525 \mathrm{~nm}$ increased with the increase in the ascorbic acid concentration, which means that ascorbic acid contributed to the PSPC stability and could be used as copigment. The absorption value at $525 \mathrm{~nm}$ decreases with the increase in concentration of $\mathrm{Na}_{2} \mathrm{SO}_{3}$, which indicates that $\mathrm{Na}_{2} \mathrm{SO}_{3}$ has a bad effect on PSPC stability.

\section{Conclusion}

In the basis of RSM experiment, the optimum extraction conditions of PSPC are the extraction temperature of $60^{\circ} \mathrm{C}$, extraction time of $1 \mathrm{~h}$, solid-liquid ratio of $1: 30$, and acidified ethanol aqueous solution concentration of $80 \%$, and the 
TABLE 5: Effects of ascorbic acid and $\mathrm{Na}_{2} \mathrm{SO}_{3}$ on PSPC stability.

\begin{tabular}{cccccc}
\hline \multicolumn{5}{c}{ Ascorbic acid concentration $(\mathrm{mg} / \mathrm{L})$} \\
\hline \multirow{4}{*}{$A$} & 0 & 0.2 & 0.4 & 0.6 & 0.8 \\
& 0.721 & 0.732 & 0.758 & 0.792 & 0.799 \\
\hline \multirow{5}{*}{ Concentration of $\mathrm{Na}_{2} \mathrm{SO}_{3}(\mathrm{mg} / \mathrm{L})$} \\
\hline & 0 & 0.01 & 0.02 & 0.04 & 0.06 \\
& 0.698 & 0.657 & 0.642 & 0.638 & 0.632 \\
\hline
\end{tabular}

extraction yield of PSPC is $11.6355 \mathrm{mg} / \mathrm{g}$. $\mathrm{Fe}^{3+}$ and $\mathrm{Al}^{3+}$ can contribute the stability of PSPC, but $\mathrm{Cu}^{2+}, \mathrm{Zn}^{2+}$, and $\mathrm{Pb}^{2+}$ would decrease the stability of PSPC. Ascorbic acid can significantly increase the stability of PSPC which can be used as copigment, and $\mathrm{Na}_{2} \mathrm{SO}_{3}$ would have bad effect on the stability of PSPC.

\section{Acknowledgments}

This work was supported by the Research Fund of National 12th Five-Year Plan of China (2011AA100806-3), the National Natural Science Foundation of China (31171703 and 31101361), Industry-Academia Cooperation Innovation Fund Projects of Jiangsu Province (BY20120460), Fundamental Research Funds for the Central Universities (JUSRP211A30), and the Open Project Program of State Key Laboratory of Dairy Biotechnology, Bright Dairy \& Food Co. Ltd. (SKLDB2011002).

\section{References}

[1] Z. Yang, Y. Wang, and L. Gao, "Research progress on purple sweet potato colore," Journal of Qingdao University (E\&T), vol. 19, no. 2, pp. 32-36, 2004.

[2] Z. Fang and Y. Ni, "Research progress on physiological functions of anthocyanins," Guangzhou Food Science and Technology, vol. 17, no. 3, pp. 60-62, 2001.

[3] G. Lu, X. Lan, X. Lou et al., "Study on physical and chemical properties of red pigments from purple sweet potato (PSP)," Journal of Zhejiang Agricultural University, vol. 22, no. 3, pp. 308-311, 1996.

[4] Y. Liu, L. Zhu, Z. Han et al., "Anti-oxidative effect of Ipomoea Batatas Poir $\mathrm{Cv}$ anthocyanins on mice irradiated by $60 \mathrm{Co}$ gamma ray," Acta Acadimae Qingdao Umvesitatis, vol. 41, no. 1, pp. 46-51, 2005.

[5] X. Meng, X. Cu, F. Wang et al., "In vivo antioxidant activity of sweet -potato anthocyanins in aged mice," Medical Journal of Qilu, vol. 20, no. 5, pp. 394-399, 2005.

[6] W. Han, Extraction, Composition Analasis, Stability and Antioxidant Activity of Anthocyanins from Purple Sweet Potato, Nanjing Agriculture University, 2008.

[7] Z. Wang, Study on the Technology Conditions of Extraction and Purification and Property of Purple Sweetpotato Color, Southwest University, 2010.

[8] J. Li, Study of the Extraction, Purification by Membrane Technology and Stability of Anthocyanin Pigment from Purple Sweet Potato, Nanchang University, 2007. 

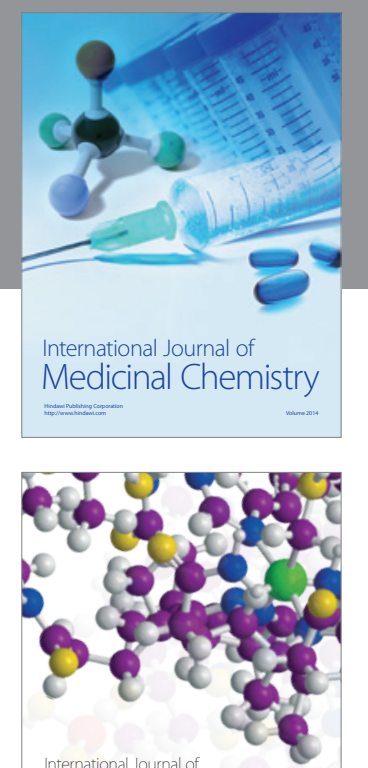

\section{Carbohydrate} Chemistry

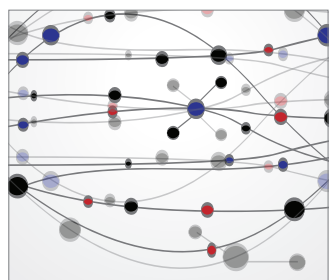

The Scientific World Journal
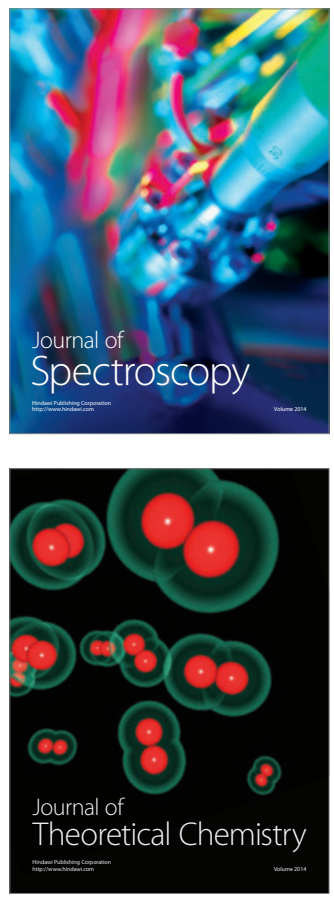
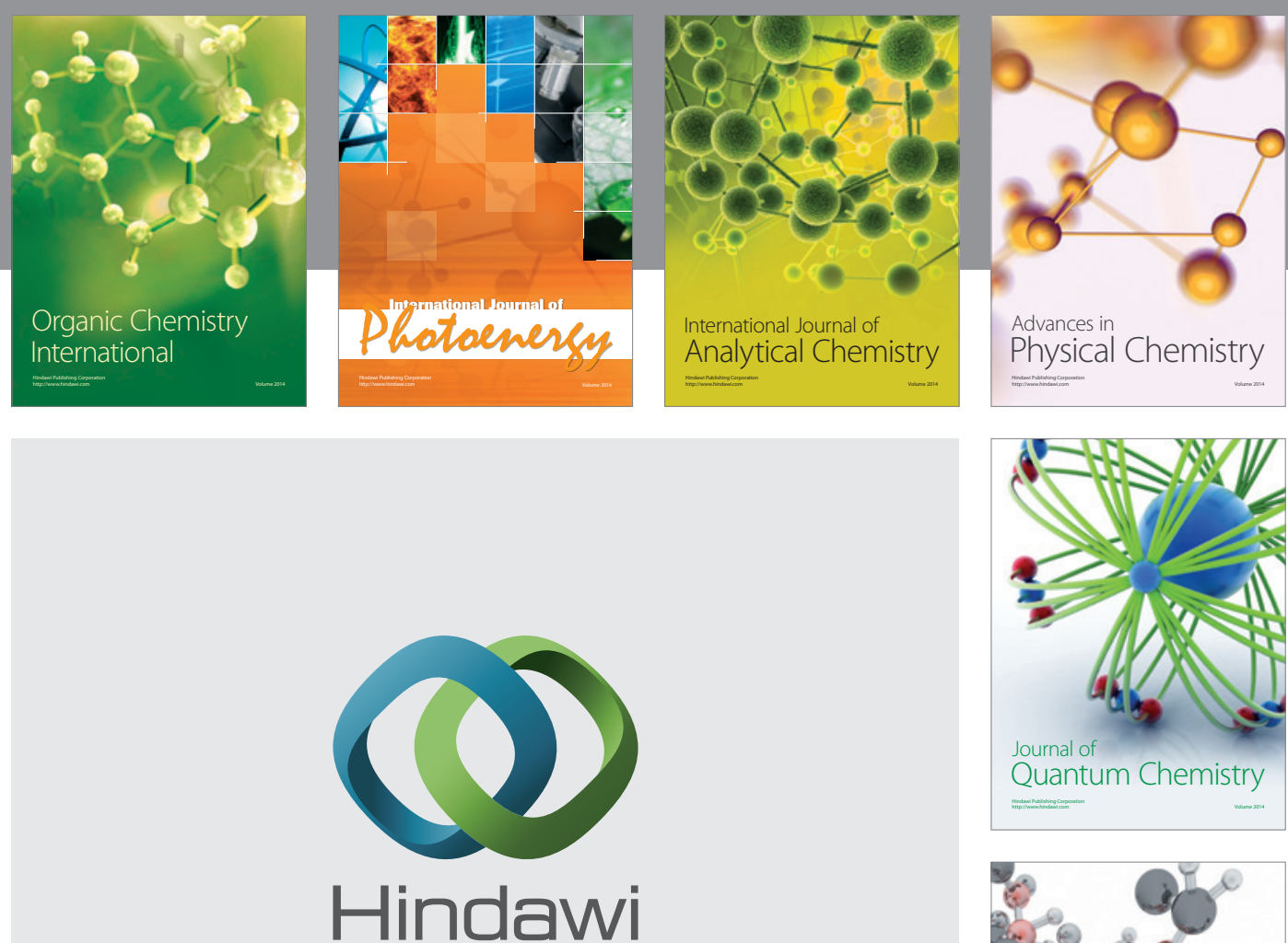

Submit your manuscripts at

http://www.hindawi.com

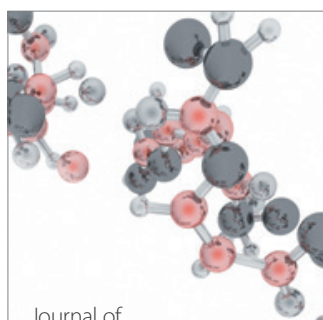

Analytical Methods

in Chemistry

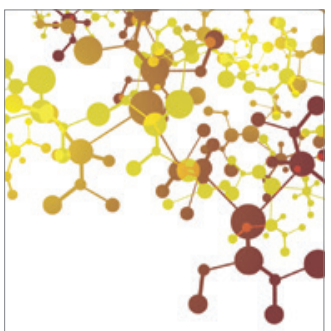

Journal of

Applied Chemistry

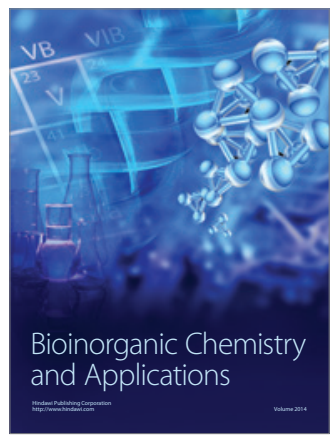

Inorganic Chemistry
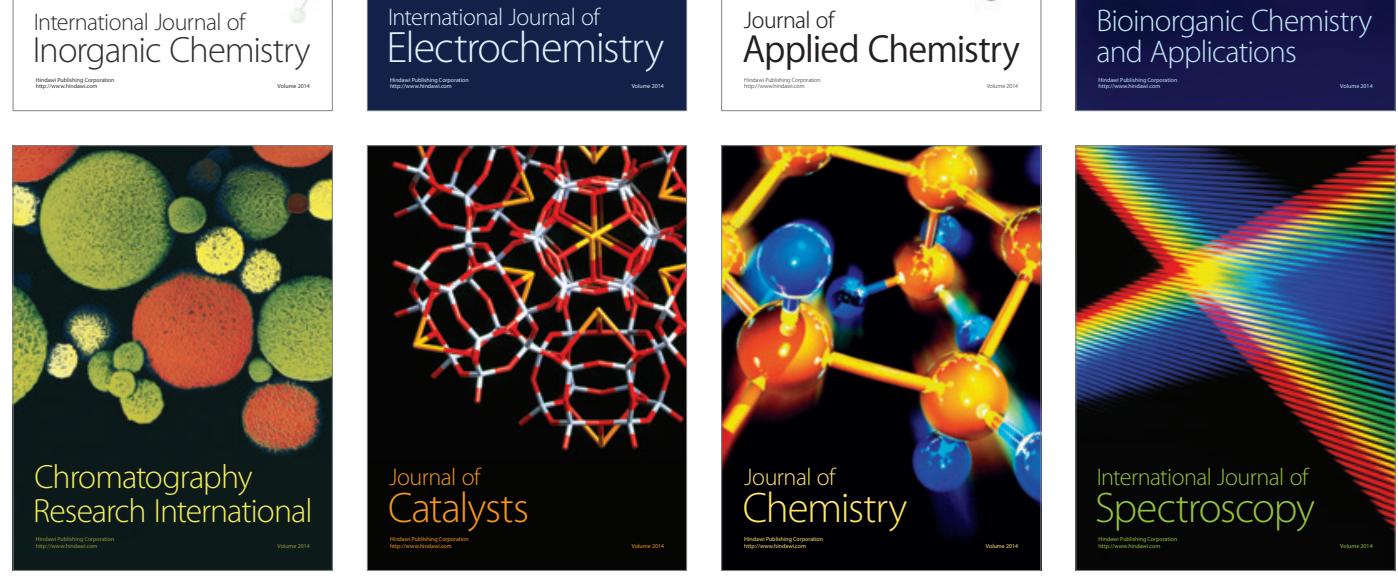